\title{
ANAESTHESIA FOR MICROLARYNGOSCOPY AND DEFINITIVE SURGERY
}

\author{
R. Rajagopalan, M.D., Foster Smith, M.D., \\ and P. R. RaMachandRAN, F.R.C.P.(C)"
}

SANDERS, ${ }^{1}$ IN 1967, introduced the use of the Venturi principle for intermittant positive pressure breathing for bronchoscopy by attaching a jet injector to the bronchoscope. Sanders' injector consists of a simple 2-inch 16-gauge cannula which can be attached to the proximal end of the bronchoscope. A jet of oxygen blown through the injector cannula will generate sufficient force to draw in room air and deliver a large volume of air at a substantial positive pressure. The supply of oxygen can be rendered intermittent by the use of Bird Mark ux ventilator. ${ }^{2}$

Spoere ${ }^{3}$ reported satisfactory ventilation during bronchoscopy, employing Sanders injector principle. The object of this study was to evaluate the extension of Sanders' technique of ventilation for microlaryngoscopy and definitive surgery. Arterial blood gas studies were done to evaluate the adequacy of oxygenation and ventilation during the procedure.

\section{Methods}

This study consists of 16 unselected adult patients of both sexes, varying from 36 to 80 years of age. Six of them had only microlaryngoscopy (Table I) and the rest had both microlaryngoscopy and surgery (Table II). ASA risk status of the patients is given in Table III.

TABLE I

\begin{tabular}{lc}
\hline \multicolumn{1}{c}{ Disease } & $\begin{array}{c}\text { Number of } \\
\text { cases }\end{array}$ \\
\hline Laryngitis & 3 \\
Carcinoma of larynx & 2 \\
Vocal cord polyp & 1 \\
\hline
\end{tabular}

TABLE II

\begin{tabular}{lc} 
Disease & $\begin{array}{c}\text { Number of } \\
\text { cases }\end{array}$ \\
\hline Carcinoma of larynx & 3 \\
Vocal cord polyp & 4 \\
Hyperkeratosis & 2 \\
Cyst pyriform fossa & 1 \\
\hline
\end{tabular}

\footnotetext{
"Department of Anaesthesia, Wellesley Hospital, University of Toronto, Toronto, Ontario, Canada.
}

83

Canad. Anaesth. Soc. J., vol. 19, no. 1, January 1972 
TABLE III

\begin{tabular}{cc}
\hline ASA risk & $\begin{array}{c}\text { Number of } \\
\text { cases }\end{array}$ \\
\hline 1 & 11 \\
2 & 5 \\
3 & 1 \\
\hline
\end{tabular}

Patients were premedicated with meperidine $50 \mathrm{mg}$ and atropine $0.6 \mathrm{mg}, 45$ minutes prior to their arrival in the operating room. They breathed 100 per cent oxygen by mask for 3 minutes before induction. Induction was with a sleep dose of 2.5 per cent thiopentone. Further doses of thiopentone were given when necessary to maintain unconsciousness. Intravenous succinylcholine was administered intermittently to provide adequate muscle relaxation. The mean doses of thiopentone and succinylcholine required in this series were $940 \mathrm{mg}$ and $620 \mathrm{mg}$ respectively.

After the patient had lost consciousness and muscular relaxation was adequate, the suspension laryngoscope was placed in position and the injector cannula was inserted into one of the two light channels in the instrument. The inspiratory pressure, flow rate and the expiratory pause of Bird Mark in Ventilator were so adjusted as to achieve a satisfactory expansion of the chest, as observed clinically.

Arterial blood samples were drawn and numbered as follows:

Sample No. 1 - Control (before oxygenation and induction)

Sample No. 2 - 10 minutes after insertion of laryngoscope

Sample No. 3-At the end of the procedure. (Time elapsed since the insertion of laryngoscope varied from a minimum of 20 minutes to a maximum of 90 minutes.) Sample No. 4-20 minutes after reaching the recovery room, patient breathing oxygen 4 liters/minute through a nasal catheter.

\section{ResULts}

The raw data is presented in Table IV. A comparison of the pre-operative $\mathrm{pH}$, $\mathrm{PCO}_{2}$ and $\mathrm{PO}_{2}$ values was made with those obtained during the procedure and in the immediate post operative period using the standard $t$ test. The adequacy of oxygenation and $\mathrm{CO}_{2}$ elimination during the procedure and in the immediate post operative period is indicated by the satisfactory blood gas values obtained (Table IV).

\section{Discussion}

The term microlaryngoseopy is self explanatory. Definitive surgery of the larynx refers to the surgery of the larynx "cell by cell." Both these procedures require the combined use of suspension laryngoscope and operating microscope. For a satisfactory performance of these procedures it is mandatory that the larynx is immobile, relaxed and continuously under vision without the interference of an endotracheal tube, permitting the surgeon uninterrupted free access to the larynx for prolonged periods. 


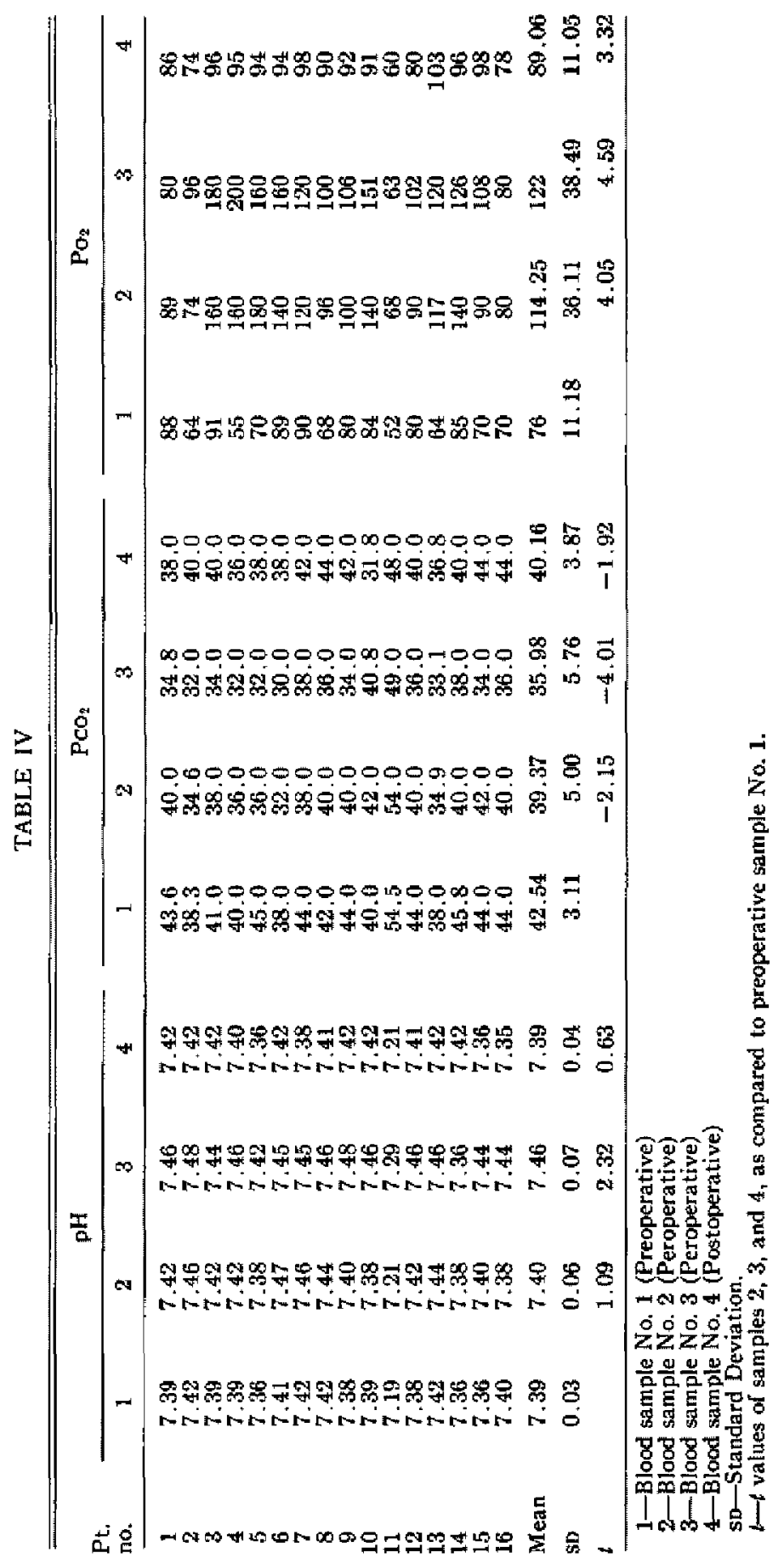


The technique of anaesthesia employed in this study provided several advantages. The required conditions of adequate ventilation for prolonged periods, adequate anaesthesia and muscle relaxation were all made possible, facilitating uninterrupted and unhurried microlaryngoscopy and surgery. The application of Sander's technique of ventilation overcomes many of the problems described by Desanto and Carney ${ }^{4}$ in the performance of these procedures. To minimise possible air leaks, it is essential that the suspension laryngoscope is carefully positioned with its proximal end lying just above the larynx.

In this study, the technique of anaesthesia and ventilation has been safely employed in 16 patients for procedures lasting from 20 to 90 minutes. Despite the large doses of thiopentone and succinylcholine used there was no clinical evidence of cardio-respiratory depression either during surgery or in the post operative period.

\section{Summary}

We have described what appears to us a most satisfactory anaesthetic technique for microlaryngoscopy and definitive surgery of the larynx. The method of ventilation employed was basically an extension of Sanders' injector technique, using the Venturi principle. Blood gas determinations in a series of 16 patients showed oxygenation and ventilation to be satisfactory. From the endoscopist's point of view, this technique offered several advantages:

1. The endoscopic procedure need not be interrupted to ventilate the patient.

2. Since the patient is adequately oxygenated and ventilated the time for the procedure is not limited.

3. There is no endotracheal tube to interfere with the free access and visualisation of the larynx.

\section{REFERENCES}

1. SAnders, R, D. Two ventilating attachments for bronchoscopes. Delaware M, J., 39: 170 (1967).

2. Spoerez, W, E. Ventilation through an open bronchoscope (Preliminary Report). Canad. Anaesth. Soc. J., 16: 61 (1969).

3. Spoenel, W. E. Ventilation during bronchoscopy. Canad. Anaesth. Soc. I., I8: 178 (1971).

4. DeSanto, L. W, \& Canney, M. 'T'. Microlaryngoscopic surgery. Arch. Otolaryng-, 91 : 324 (1970). 